\title{
Performance and Emissions of Iso-stoichiometric Ternary GEM Blends on a Production SI Engine
}

Sileghem, L. ${ }^{* 1}$, Coppens, A. ${ }^{1}$, Casier, B. ${ }^{1}$, Vancoillie, J. ${ }^{1}$, Verhelst S. ${ }^{1}$

${ }^{1}$ Department of Flow, Heat and Combustion Mechanics, Ghent University, Sint-

Pietersnieuwstraat 41, B-9000 Ghent, Belgium

*Corresponding author:

Email: Louis.Sileghem@UGent.be

KEYWORDS - Ternary blends, methanol, ethanol, flex fuel vehicles, SI engine

ABSTRACT - Removing the biomass limit is one of the great challenges to further enlarge the share of renewable ethanol as alternative for fossil fuels. One of the possible solutions for this constraint are the ternary GEM (Gasoline-Ethanol-Methanol) blends. The air-to-fuel ratio of these blends is hereby chosen at the value of an E85-blend (9.75 $\mathrm{kg}$ air/ $\mathrm{kg}$ fuel) while the ethanol is replaced by methanol/gasoline and therefore these blends are called 'isostoichiometric'. If the methanol is produced out of renewable sources, these blends can help extend the part of clean fuels on the market. The ternary blends show few differences in physical properties for the total range of possible blends and are considered as drop-in alternatives to the original E85-blend for a flex fuel engine. In this paper the performance and engine-out emissions of four of these GEM-blends were examined on a 4 cylinder $1.81 \mathrm{PFI}$ production engine. A single cylinder engine with high compression ratio was used for a preliminary study of the knock behavior of these blends. The measurement results are compared with those on neat gasoline, methanol and ethanol to demonstrate the potential of these ternary blends as a fossil fuel alternative. All the GEM fuels which were tested gave very similar results to E85 and can therefore indeed be used as 'drop-in' fuels for flex-fuel vehicles. 


\section{INTRODUCTION}

It is well-known that fossil fuels are being consumed worldwide in enormous amounts and that the demand for energy keeps increasing every year at high rates. The transportation sector is one of the big consumers and during the last decades people have become aware that we cannot depend on these fossil fuels forever because of the shrinking reserves, negative climate change and bad air quality [1]. Hydrogen [2] and electrification are widely cited as possible solutions these days. Electrification and hydrogen are widely investigated and electric city cars are already in use. Nevertheless, the low volumetric energy density of batteries and hydrogen provide these vehicles with a limited range, compared to conventional ICE vehicles. A transition to either hydrogen vehicles or battery electric vehicles will result in increases in both vehicle and infrastructure costs making it questionable if they will become competitive with vehicles running on liquid fuels in the near future.

Driven by the Renewable Energy Directive in the EU [3] and The Energy Independence and Security Act in the US [4], biofuels are likely to be used at increasingly high concentrations over the next years due to the compatibility with modern vehicles and the distribution and fueling infrastructure. For now, bio-ethanol has the lion's share when it comes to non-petroleum-derived transportation energy. Currently, the largest part of the bio-ethanol is used in low level blends but it can also be used in high level blends like E85 (nominally $85 \mathrm{v} / \mathrm{v} \%$ ethanol in gasoline) in flex-fuel vehicles. Flex-fuel vehicles are able to run on ethanol concentrations from $0 \%$ up to $85 \%$ by volume in gasoline. There are already millions of flex-fuel vehicles on the market but few of these vehicles regularly use E85 [5]. Nevertheless, they represent a potentially large market for alcohol fuels. 
Despite of the projected growth, bio-ethanol is not considered to be viable in the long term as a substitute for fossil fuels, due to the biomass limit [6]. This biomass limit is different for each country, and depends on the amount of biomass that can be grown there, the amount of energy required by the country, any impact of land-use change that may arise, and limits set by any impact on the food chain [7], [8]. It has been estimated that this limits the potential of biofuels to about $20 \%$ of the energy demand in 2050 [9].

Compared to ethanol, methanol is actually more versatile from a production point of view. Methanol can be produced from a wide variety of renewable sources (e.g. gasification of wood, agricultural by-products and municipal waste) and alternative fossil fuel based feed stocks (e.g. coal and natural gas). A number of workers have even proposed a sustainable closed-carbon cycle where methanol is synthesized from hydrogen, produced from renewable electricity, and atmospheric $\mathrm{CO}_{2}$, thus forming a liquid hydrogen carrier and making it an 'electrofuel' [10]. Methanol has been successfully used in large-scale fleet trials [11] and studied on engine test benches $[12,13]$. Because of the high octane index, high heat of vaporization and low combustion temperatures, the power and efficiency is significantly higher for methanol (and ethanol) compared to gasoline. This is certainly true for highly pressure-charged engines, where aggressive downsizing is possible on these alcohols [14].

\section{ISO-STOICHIOMETRIC TERNARY BLENDS}

Turner et al. $[7,15]$ presented the concept of ternary blends of gasoline, ethanol and methanol in which the stoichiometric air-to fuel ratio is controlled to be the same as that of conventional E85 alcohol-based fuel. In fact, starting from any binary gasoline-ethanol mixture, a ternary blend of gasoline, ethanol and methanol can be devised in which the fraction of each component is chosen to yield the same stoichiometric air to fuel ratio (for E85, this is 9.75:1 depending on the AFR 
of the gasoline which can vary somewhat). In this study the Euro 95 gasoline that was used in the experiments has an AFR of 14.4. The gasoline has been analyzed with mass spectrometry and no alcohols were found in the gasoline. In Figure 1, the concept of these ternary blends is shown for equivalent 'E85' blends. On the right side of Figure 1, the composition of normal E85 can be seen ( $85 \mathrm{v} / \mathrm{v} \%$ ethanol and $15 \mathrm{v} / \mathrm{v} \%$ gasoline). On the left side of Figure 1, the binary mixture of gasoline and methanol is shown in which all the ethanol is replaced with gasoline and methanol. This results in a M57 blend ( $57 \mathrm{v} / \mathrm{v} \%$ methanol and $43 \mathrm{v} / \mathrm{v} \%$ gasoline). In between these two blends, any iso-stoichiometric ternary blend can be determined by drawing a vertical line in Figure 1 and reading the blend ratios on the left axis of the figure (for example the yellow dotted line in Figure 1). Turner et al. [15] found that all the possible iso-stoichiometric ternary blends starting from a binary blend of gasoline and ethanol have, beside the same AFR, essentially identical volumetric energy content (based on the masses and densities of the individual components), constant octane numbers and constant latent heat. This opens the possibility to use these ternary blends as drop-in fuels for flex-fuel vehicles without the danger of upsetting the onboard diagnostics of the engine management system. If the methanol used is of a renewable and energy-secure nature then, for a fixed volume of ethanol in the fuel pool dependent on the biomass limit, an increased level of renewability and energy security is achieved. This overall situation is made possible by the fact that there are more E85/flex-fuel vehicles in existence than can currently be serviced by the E85 fuel supply chain.

Turner et al. [15] tested the drop-in ability of the iso-stoichiometric GEM blends in two flex-fuel vehicles. One vehicle was provided with a physical sensor for alcohol content and the other vehicle had a 'virtual' sensor. A physical sensor measures directly the alcohol concentration of the fuel relying on the electric permittivity or the resistance of the fuel, while a virtual sensor 
utilizes an algorithm based on the information of the other sensors of the engine to calculate the alcohol concentration. A 'virtual' sensor has the advantage that there is no additional cost in hardware.

During vehicle testing, the hypothesis that iso-stoichoimetric GEM blends can function as dropin alternatives to binary ethanol-gasoline blends has been confirmed. There were only two malfunction lights when running on the binary gasoline-methanol blend with the vehicle with the 'virtual' sensor. Turner et al. [15] stated that this could be due to phase separation as the vehicle was not subjected to road shocks or accelerations on the test bench and that some form of cosolvent might be necessary when methanol and gasoline are blended together. Compared to the gasoline tests on the same vehicles, there was an overall efficiency improvement of approximately 5\% when using the alcohol blends. Turner et al. [15] performed also cold start tests. The only fuel blend which failed the cold start test was the normal E85 blend. This is to be expected as ethanol is harder to start than gasoline or methanol, and so reducing the proportion of this component and replacing it with larger amounts of the other two would only be expected to improve the situation. This means that there is the possibility with GEM blends to effectively extend gasoline displacement during winter months when currently, with existing commercial E85 fuels, the ethanol content is decreased to levels close to $70 \%$ in order to maintain cold startability. A year-round fixed blend ratio is therefore a possibility.

It is important to notice that the tests were conducted on a vehicle and the emissions were measured at the end of the tailpipe without knowing what the ECU was actually doing. As a result, measurements on an engine test bench and engine-out emissions are indispensable to learn the full effect of replacing ethanol by methanol/gasoline in the GEM-blends. This is addressed in this study where different iso-stoichiometric blend are tested on engine test benches. 
Next to the hypothesis, other benefits of the GEM-blends were discussed like the potential economic advantage. Turner et al. [15] showed that with wholesale prices of $\$ 3.11, \$ 2.30$ and \$1.11 per US gallon for gasoline, ethanol and methanol respectively, the price of the blends can be made significantly lower than gasoline on an energy basis. With these prices, with ternary blends containing more than $25 \%$ by volume of methanol, a reduction in motoring costs could be realized just through a reduction in the relative price of the fuel versus gasoline. Since the vehicles would be expected to become more efficient when operated on the high-blend alcohol fuels, one would expect another reduction in operating costs.

Another advantage is that for flex-fuel vehicles, there is no need for range anxiety, which is a major obstacle for electric vehicles, because these vehicles are still able to run on gasoline. The user would be able to run on a high-alcohol GEM blend, on which the vehicle would be significantly cheaper to operate but with a lower range due to the lower volumetric energy content of the alcohol fuel, or on gasoline, when he would like to travel longer distances before refueling.

In this study, four different GEM blends are investigated. The composition and the properties of the blends are shown in Table 1. There are two binary blends: Blend A representing normal E85 and the iso-stoichoimetric methanol-gasoline Blend D with $57 \mathrm{v} / \mathrm{v} \%$ methanol. This methanolgasoline blend has $1 \mathrm{v} / \mathrm{v} \%$ methanol more than in the study of Turner et al. [15] because of the AFR of the gasoline used here. The two other blends are ternary blends of which the ethanol content is halved each time starting from E85. The density is not shown in the table because there is a change in volume on mixing due to partial molar volume effects. There is an interaction between the large molecules such as those found in gasoline with the smaller alcohol 
molecules. In this study, this effect was not considered when calculating the volumetric LHV. For modern engine management systems, one would not expect any issues because of varying densities for 'equivalent' mixtures because these systems already have to take into account varying fuel densities and AFR's of the current fossil fuels.

The octane numbers were not measured for this study. One can assume similar octane numbers as in the study of Turner et al. [15] in which the octane numbers were measured for the different blends. The octane numbers are shown in Figure 2. As can be seen, octane numbers do not vary much for the different blends and even the sensitivity is more or less constant.

Less information is available about the combustion of GEM blends. Sileghem et al. [16, 17] investigated the laminar burning velocity of alcohol-hydrocarbon blends. Methanol has the highest laminar burning velocity followed by ethanol and gasoline. For the different blends, it is expected that they have similar laminar burning velocities, although less is known about the laminar burning velocity of alcohol-blends at higher temperature and pressure.

Most performance and emission results are expected to be at an intermediate level between those of pure gasoline and pure alcohols. The variation between the different blends is not expected to be substantial according to the results of Turner et al. [15] on a flex fuel vehicle. This is discussed in the 'Results and Discussion' section.

\section{PROPERTIES OF LIGHT ALCOHOLS COMPARED TO GASOLINE}

Alcohols exhibit several favorable properties as a fuel for spark-ignited engines. Compared to gasoline, methanol and ethanol have the potential to increase engine performance and efficiency. These interesting properties are more marked with methanol (being the lightest alcohol) and thus the potential for increase in power and efficiency is highest for this fuel. An efficiency study 
between hydrogen, gasoline and methanol has been done which showed the favorable properties of light alcohols as a fuel for internal combustion engines [12].

The most important properties, compared to gasoline, include:

1. High heat of vaporization, which in combination with the low stoichiometric air to fuel ratio leads to high degrees of intake charge cooling as the injected fuel evaporates. This effect is more distinct for DI engines and provides an increased charge density. Lower in-cylinder temperatures will also have a positive effect on NOx-emissions and heat losses.

2. Elevated knock resistance, which is partly due to the considerable cooling effect. This opens opportunities for increased power and efficiency by applying higher compression ratios, optimal spark timing and aggressive downsizing. In combination with aggressive downsizing significant efficiency gains can be achieved without the need for using a rich mixture at high load.

3. The higher laminar burning velocity of alcohols in comparison to gasoline results in a more isochoric combustion, approaching the ideal cycle more closely. An additional advantage of this increased laminar burning velocity is the potential of broadening the EGR working range.

In Table 2, the properties of gasoline, methanol and ethanol relevant to their use in internal combustion engines are summarized.

\section{EXPERIMENTAL SETUP}

\subsection{I four-cylinder engine}

Experimental tests were performed on a 1.8 1 SI PFI 4-cylinder production engine that has been modified to run on gasoline, alcohol and hydrogen. The engine was manufactured by Volvo and its specifications are given in Table 3. The engine is equipped with 4 alcohol compatible liquid fuel injectors (Racetronic 48INJL) which are fed through a stainless steel fuel rail, ensuring methanol compatibility. 
A MoTeC M800 ECU is used to control ignition timing, start of ignition, injection duration and intake valve timing.

The exhaust gas oxygen content was measured by a Maihak Oxor-P S710 (paramagnetic). Other exhaust gas components like $\mathrm{NOx}, \mathrm{NO}, \mathrm{CO} 2$ and $\mathrm{CO}$ were measured by a Maihak Multor 610 (non-dispersive infrared). The fuel flow was measured gravimetrically (Mettler Toledo type ICS429) and the air flow by a MAF-sensor (Bosch type 0280217 121). A direct reading of lambda is given by a Bosch wide band lambda sensor and a digital AFR meter that has been calibrated for gasoline and methanol. Cylinder pressure measurements were possible using a spark plug pressure sensor, a piezo-electric Kistler type 6118AFD13. A piezo-resistive Kistler type $4075 \mathrm{~A} 10$ sensor placed in the intake manifold close to the inlet valves was used for pegging the cylinder pressure. The crank angle was recorded using a Kistler crank angle encoder type COM2611.

The power is dissipated by a Schenk eddy current brake which also regulates engine speed. The load is controlled by a fly-by-wire throttle valve combined with the ECU injection and ignition control.

\section{Single cylinder engine}

The single cylinder engine used in this study is based on an Audi/NSU research DI diesel engine. The diesel injector was replaced by a spark plug, the compression ratio was decreased, a flat piston was used and the engine was converted for flex-fuel operation using similar adjustments as for the Volvo 1.8 1. The specifications are given in Table 3. This engine has been used for a preliminary investigation of whether a similar knock behavior can be expected for the different GEM blends. Knock could be triggered easily because of the higher compression ratio of this engine, compared to the 4 cylinder Volvo engine. 


\section{Measurement procedure}

The results presented in the next section were acquired during steady state operating conditions at various engine speeds and loads. These loads were always controlled by the throttle valve. The basic engine map, which contains the ignition timing and the injection duration for alcohols, was adapted for the specific blends in order to preserve stoichiometry and to maintain MBT timing. This stoichiometric operation was chosen to maximize the conversion rate of the TWC.

Next to the four GEM blends (see Table 1) that were investigated, measurements have been done on pure methanol, pure ethanol and gasoline. There will be a comparison with these fuels where possible.

\section{RESULTS AND DISCUSSION}

In the next section, the performance of the GEM blends will be evaluated and compared to some results on methanol, ethanol and gasoline on the same engine. Secondly, the pollutant emissions of the GEM blends will be discussed and finally, the knock behavior of the GEM blends will be investigated on the single cylinder engine with a high compression ratio. The knock limit will be compared to methanol, ethanol and two different gasolines with a RON of 95 and 98 .

\section{Performance}

Figure 3 shows the brake thermal efficiency for all blends at a load of $40 \mathrm{Nm}$ (2.82 bar BMEP) for a range of engine speeds. The hypothesis that all iso-stoichiometric blends have similar BTE is confirmed as all values fall within the experimental uncertainty. This statement is valid for all loads tested here.

Figure 4 displays the comparison with gasoline, methanol, ethanol and a mean value for the GEM blends for 40 and $80 \mathrm{Nm}$. This mean value is representative for all mixture compositions as the differences between the GEM blends are within the experimental uncertainty. When 
compared to gasoline, it is clear that the GEM blends show significant efficiency gains. The mean value for the GEM blends is similar to the BTE of pure ethanol. Pure methanol clearly still has superior performance. This is explained by the higher burning velocity of methanol, the smaller in-cylinder cooling losses because of the charge cooling due to evaporation and the high heat capacity of the burned methanol. An extensive comparison between the pure fuels hydrogen, gasoline and methanol can be found in Reference [12].

In Figure 4, the efficiencies of all the fuels increase as the delivered torque increases. As a result of the increasing torque, the mechanical efficiency increases strongly. With an increasing torque, the flow losses increase because of the larger flow, but the pumping losses decrease due to a larger TP. The increase in mechanical efficiency is clearly the dominating factor.

The BTE of the fuels tested for this study can be seen to show little sensitivity to the engine speed. There seems to be a small drop with increasing engine speed. On the one hand, the increasing air flow with engine speed causes higher flow losses but on the other hand, as seen from the TP curve in Figure 5, the throttle opening has to be increased with engine speed to keep the torque output constant, which decreases the throttling losses. Both effects seem to almost cancel each other out but the net effect is a decrease in BTE.

BSFC does - as expected after the discussion on BTE - not depend on mixture composition as seen on Figure 6 because of the similar LHV of the four GEM blends. BSFC is still considered as the main disadvantage of fuels containing alcohols due to their decreased LHV. While the GEM blends display similar BTE as pure ethanol, their BSFC is less penalized as for pure methanol. This can be derived from Figure 7 in which a comparison of the BSFC of gasoline, methanol, ethanol and a mean value for the GEM blends for 40 and $80 \mathrm{Nm}$ is shown. Despite the better efficiency on GEM blends, this engine will consume 32\% more GEM fuel than when it 
is running on gasoline on a volume basis. This difference will be smaller for modern highly downsized and pressure charged engines with direct injection in which the properties of alcohols will have greater benefits.

In Figure 8, the volumetric efficiency is shown at a load of $40 \mathrm{Nm}$ for the four different isostoichiometric GEM blends. The volumetric efficiency is defined as:

$$
\eta_{\mathrm{v}}=\frac{\dot{\mathrm{m}}_{\text {fuel+air }}}{\dot{\mathrm{m}}_{\text {theoretically }}}
$$

with $\dot{\mathrm{m}}_{\text {fuel+air }}$ the actual mass flow of fuel and air entering the cylinders during the intake stroke and $\dot{\mathrm{m}}_{\text {theoretically }}$ the theoretical mass flow that could enter the cylinders under reference conditions.

All the possible iso-stoichiometric ternary blends have essentially identical volumetric energy content and constant latent heat. As a result of the similar efficiencies of the GEM blends, the volumetric efficiency is largely unaffected by the blend composition for all measuring points. An increase of the volumetric efficiency with engine speed for a fixed torque is explained by the drop in BTE with engine speed. More fuel is needed for the same torque output. It is expected that every parameter can stay equal within the control systems of the engine. This is also reflected in the throttle position and the MBT ignition timing for a specified load, as can be seen in Figure 5 and Figure 9. MBT-timing is set by hand and, as a result, slight deviations can occur in the measurements. Selected MBT timing for almost all blends are similar with a maximum deviation of $1^{\circ} \mathrm{ca}$. Due to the identical properties of the GEM blends, resulting in almost identical performance and efficiencies, the exhaust temperatures of the different blends are quasi 
equal, see Figure 10. This can be important for turbocharged engines to make sure that the turbine inlet temperature does not exceed the maximum allowed temperature of the materials.

The in-cylinder pressure measurements can be used to obtain information regarding the combustion process in the engine, in terms of heat release and mass fraction burned. In Figure 11 , the heat release rates of the four different GEM blends are shown. These are calculated from the in-cylinder pressure measurements. As seen on the figure, all heat release rates are close to each other. As a result, the burn durations for the different GEM blends are very similar. The ignition delay ( $0-2 \%$ mass fraction burned), the $0-10 \%$ and $0-50 \%$ mass fraction burn durations are plotted in Figure 12 as a function of engine speed, which shows the similar burning velocities of the GEM fuels at these operation points. The $\mathrm{CoV}$ of the IMEP as function of engine speed is shown in Figure 13. All CoV values are low enough (lower than 3\%) to have reproducible results.

\section{Emissions}

In this section, the trends of emissions of $\mathrm{NO}_{\mathrm{x}}$ and $\mathrm{CO}$ are shown and discussed. Emissions of unburned fuel were not measured because for flame ionization detectors as used in our exhaust gas analyzers, the reaction time for oxygenated hydrocarbons is impracticably long and thus realistic values are not possible. Oxygenated species such as unburned methanol and formaldehyde are commonly found in the exhaust gases of methanol engines. Using a flame ionization detector might thus lead to an underestimation of the total unburned hydrocarbons. Figure 14 compares the engine-out $\mathrm{NO}_{\mathrm{x}}$ emissions for the four GEM blends at a load of $40 \mathrm{Nm}$. As can be seen, the highest $\mathrm{NOx}$ emissions are on gasoline and the lowest $\mathrm{NO}_{\mathrm{x}}$ emissions are on methanol. All the $\mathrm{NO}_{\mathrm{x}}$ emissions on the GEM blends are somewhere between gasoline and 
methanol. The lower combustion temperature of the alcohol fuels are responsible for the lower $\mathrm{NO}_{\mathrm{x}}$ emissions since most $\mathrm{NO}_{\mathrm{x}}$ is produced by the thermal mechanism wich is very dependent on temperature. The lower $\mathrm{NO}_{\mathrm{x}}$ emissions at lower engine speeds might be caused by elevated levels of internal EGR since the vacuum in the intake due to throttling is quite considerable at this load of $40 \mathrm{Nm}$. For the GEM blends it is remarkable that there is an increase in $\mathrm{NO}_{\mathrm{x}}$ emission with increased gasoline content in the mixture. This variation with gasoline content and thus total alcohol concentration for all other measurements could be ascribed to the slight variation in flame temperature.

The engine-out $\mathrm{CO}$ emissions for the different blends are compared in Figure 15 for a load of 40 Nm. All GEM fuels gave more or less the same CO emissions considering the error bars. According to some authors, due to the oxygenated nature of alcohols which might cause a more complete combustion, the CO emissions of alcohol fuels should be lower than gasoline [18]. Thus, it is expected that the $\mathrm{CO}$ emissions of the blends are higher than the $\mathrm{CO}$ emissions of pure methanol and lower than gasoline. This trend could not be seen in the measurements. Both gasoline and methanol gave similar $\mathrm{CO}$ emissions. It is not possible to conclude that the $\mathrm{CO}$ emissions are actually lower or higher for the blends because the error bars overlap and the fact that slight deviations from stoichiometric operation might have a bigger influence on the $\mathrm{CO}$ emissions than the fuel type.

\section{Knock behavior}

GEM blends should have a bigger advantage over gasoline in modern pressure charged engines because these fuels suppress knock more than gasoline. For the Volvo 4 cylinder engine, no knock occurred during the measurements on all the different fuels and MBT timing could be set for every load and engine speed. Turner et al. [7] investigated the octane numbers of the GEM 
blends and found that the octane numbers as well as the sensitivity of the GEM blends was quasi constant. As a result, it is expected that the different GEM fuels have the same knock behavior. To investigate the statement that all such blends exhibit quasi constant RON and MON, all blends and components (pure methanol, ethanol and gasoline) are tested on a single cylinder test engine with high compression ratio. The properties of this test engine are listed in Table 3 . At an operating point of $25 \mathrm{Nm}(\mathrm{BMEP}=7.713 \mathrm{bar})$ and $2000 \mathrm{rpm}$, ignition timing is advanced until an intermediate knocking condition is obtained. This intermediate knocking condition is assessed by audible signals and the third derivative of the pressure signal [19]. Next to the gasoline with RON 95, which was used to make the blends, a gasoline with RON 98 was used. The results of this experiment are shown in Figure 16. As can be seen, all blends have similar knocking behavior resulting in the same ignition timing before knock occurs. The ternary blends display the same ignition timing as pure ethanol. The equivalent 'E85' GEM blends are close to pure ethanol which explains this behavior. Methanol still has superior knock resistance mainly because of the additional cooling effect due to its latent heat of vaporization combined with the lower AFR. This effect could be further enhanced by direct injection. Finally, all alcohol containing mixtures score significantly better than the two gasolines tested in this engine.

\section{CONCLUSION}

This paper investigates the hypothesis that iso-stoichiometric ternary blends can be used as dropin fuels for spark-ignited flex-fuel engines. Confirmation of similar BTE, volumetric efficiency, BSFC and knock behavior is reported for the tested operating points. The comparison with gasoline is made to emphasize the potential for efficiency improvements and emission reduction. NOx formation displays small variations with mixture composition due to slight peak temperature variations. The disadvantage of increased BSFC in comparison to gasoline is the 
ever present drawback of alcohol containing fuels. Further efficiency gains can be attained by applying aggressive downsizing with higher compression ratio, direct injection and turbocharging which would partly compensate the lower LHV. The GEM blend concept enables to expand the share of bio-derived or $\mathrm{CO}_{2}$-neutral synthetic fuels without the need for large structural modifications. All these considerations pave the way for large scale impact reduction of the transport sector on the environment.

\section{ACKNOWLEDGMENTS}

L. Sileghem and J. Vancoillie gratefully acknowledge a Ph. D. fellowship (FWO11/ASP/056 and FWO09/ASP/030) provided by the Research Foundation Flanders. 


$\begin{array}{ll}\text { Abbreviations } & \\ \text { AFR } & \text { Air to Fuel Ratio } \\ \text { BMEP } & \text { Brake Mean Effective Pressure } \\ \text { BSFC } & \text { Brake Specific Fuel Consumption } \\ \text { BTDC } & \text { Before Top Dead Centre } \\ \text { BTE } & \text { Brake Thermal Efficiency } \\ \text { CoV } & \text { Coefficient of variation } \\ \text { CR } & \text { Compression Ratio } \\ \text { (D)OHC } & \text { (Double) OverHead Camshaft } \\ \text { ECU } & \text { Engine Control Unit } \\ \text { EGR } & \text { Exhaust Gas Recirculation } \\ \text { GEM } & \text { Gasoline, ethanol, methanol } \\ \text { ICE } & \text { Internal Combustion Engine } \\ \text { IMEP } & \text { Indicated Mean Effective Pressure } \\ \text { LHV } & \text { Lower Heating Value } \\ \text { MBT } & \text { Minimum spark advance for Best Torque } \\ \text { PFI } & \text { Port Fuel Injection } \\ \text { SI } & \text { Spark Ignition } \\ \text { TP } & \text { Throttle Position } \\ \text { TWC } & \text { Three Way Catalyst }\end{array}$




\section{REFERENCES}

[1] J.T. Houghton, Global warming: the complete briefing, , Cambridge University Press, 2004.

[2] S. Verhelst, T. Wallner, Hydrogen-fueled internal combustion engines, Progress in Energy and Combustion Science, 35 (2009) 490-527.

[3] On the promotion of the use of energy from renewable sources and amending and subsequently repealing Directives 2001/77/EC and 2003/30/EC. Directive 2009/28/EC of the European Parliament and of the Council; 23rd April 2009., in.

[4] Energy Independence and Security Act of 2007. Public Law 110-140, 110th Congress, DOCID: f:publ140.110; 2007., in.

[5] "E85: An alternative fuel," Alternative Fuels and Advanced Vehicles Data Center, US Department of Energy. http://www.afdc.energy.gov/afdc/ethanol/e85.html Accessed 23/02/2012. [6] R.J. Pearson, J.W.G. Turner, A.J. Peck, Gasoline-ethanol-methanol tri-fuel vehicle development and its role in expediting sustainable organic fuels for transport, in: IMechE Low Carbon Vehicles Conference, London, UK, 2009, pp. 1-21.

[7] J. Turner, R. Pearson, R. Purvis, E. Dekker, GEM Ternary Blends: Removing the Biomass Limit by using Iso-Stoichiometric Mixtures of Gasoline, Ethanol and Methanol, SAE Technical Paper no. 2011-24-0113, (2011).

[8] M. Specht, A. Bandi, Renewable carbon-based transportation fuels, Springer Berlin Heidelberg, Berlin, 2006.

[9] R.J. Pearson, M.D. Eisaman, J.W.G. Turner, P.P. Edwards, Z. Jiang, V.L. Kuznetsov, K.A. Littau, L. di Marco, S.R.G. Taylor, Energy Storage via Carbon-Neutral Fuels Made From CO2, Water, and Renewable Energy, Proceedings of the IEEE, 100 (2012) 440-460.

[10] G.A. Olah, A. Goeppert, G.K. Prakash, Beyond Oil and Gas: the Methanol Economy., Wiley-VCH Verlag CmbH \\& Co., KGaA, Weinheim, Germany, 2006.

[11] P.F. Ward, J.M. Teague, Fifteen years of fuel methanol distribution, in: 11th International Symposium on Alcohol Fuels Sun City, South Africa, 1996.

[12] J. Vancoillie, J. Demuynck, L. Sileghem, M. Van De Ginste, S. Verhelst, Comparison of the renewable transportation fuels, hydrogen and methanol formed from hydrogen, with gasoline Engine efficiency study, International Journal of Hydrogen Energy, 37 (2012) 9914-9924.

[13] J. Vancoillie, J. Demuynck, L. Sileghem, M. Van De Ginste, S. Verhelst, L. Brabant, L. Van Hoorebeke, The potential of methanol as a fuel for flex-fuel and dedicated spark-ignition engines, Applied Energy, 102 (2013) 140-149.

[14] M.J. Brusstar, M. Stuhldreher, D. Swain, W.M. Pidgeon, High Efficiency and Low Emissions From a Port-Injected Engine With Neat Alcohol Fuels, in: EPA VW 1.9 TDI measurements, 2002.

[15] J.W.G. Turner, R.J. Pearson, E. Dekker, B. Iosefa, K. Johansson, K.A. Bergstrom, Extending the role of alcohols as transport fuels using iso-stoichiometric ternary blends of gasoline, ethanol and methanol, Applied Energy, 102 (2013) 72-86.

[16] L. Sileghem, J. Vancoillie, J. Demuynck, J. Galle, S. Verhelst, Alternative Fuels for SparkIgnition Engines: Mixing Rules for the Laminar Burning Velocity of Gasoline-Alcohol Blends, Energy \& Fuels, 26 (2012) 4721-4727.

[17] L. Sileghem, V.A. Alekseev, J. Vancoillie, E.J.K. Nilsson, S. Verhelst, A.A. Konnov, Laminar burning velocities of primary reference fuels and simple alcohols, Fuel.

[18] D. Turner, H. Xu, R.F. Cracknell, V. Natarajan, X. Chen, Combustion performance of bioethanol at various blend ratios in a gasoline direct injection engine, Fuel, 90 (2011) 1999-2006. 
[19] M. Checkel, J. Dale, Computerized Knock Detection from Engine Pressure Records, SAE Technical Paper 860028 (1986).

Table 1: $\quad$ Properties of the GEM blends

Table 2: $\quad$ Properties of typical gasoline, methanol and ethanol relevant to internal combustion engines

Table 3: $\quad$ Engine specifications

Figure 1: $\quad$ iso-stoichiometric GEM blends equivalent to conventional E85 [15].

Figure 2: $\quad$ Measured Research (RON) and Motor (MON) octane numbers for each of the blends [7].

Figure 3: $\quad$ Brake thermal efficiency of GEM blends as a function of engine speed for a fixed brake torque of $40 \mathrm{Nm}$ (2.82 bar BMEP).

Figure 4: $\quad$ Brake thermal efficiency as a function of engine speed for different fixed brake torques of $40 \mathrm{Nm}(---)$ and $80 \mathrm{Nm}(-)$.

Figure 5: Throttle position of GEM blends as a function of engine speed for a fixed brake torque of $40 \mathrm{Nm}$ (2.82 bar BMEP).

Figure 6: Brake specific fuel consumption of GEM blends as a function of engine speed for a fixed brake torque of $40 \mathrm{Nm}$ (2.82 bar BMEP).

Figure 7: Brake specific fuel consumption as a function of engine speed for different fixed brake torques of $40 \mathrm{Nm}(---)$ and $80 \mathrm{Nm}(-)$.

Figure 8: $\quad$ Volumetric efficiency of GEM blends as a function of engine speed for a fixed brake torque of $40 \mathrm{Nm}$ (2.82 bar BMEP).

Figure 9: $\quad$ MBT of GEM blends as a function of engine speed for a fixed brake torque of 40 $\mathrm{Nm}$ (2.82 bar BMEP). 
Figure 10: $\quad$ Exhaust temperatures of GEM blends as a function of engine speed for a fixed brake torque of $40 \mathrm{Nm}$ (2.82 bar BMEP).

Figure 11: Heat release rates of GEM blends for an engine speed of $2000 \mathrm{rpm}$ and a fixed brake torque of $40 \mathrm{Nm}$ (2.82 bar BMEP).

Figure 12: $\quad$ Ignition delay (0-2\% burned), $0-10 \%$ and $0-50 \%$ burn duration of GEM blends as a function of engine speed for a fixed brake torque of $40 \mathrm{Nm}$ (2.82 bar BMEP).

Figure 13: Coefficient of variation of the IMEP of GEM blends as a function of engine speed for a fixed brake torque of $40 \mathrm{Nm}$ (2.82 bar BMEP).

Figure 14: $\quad \mathrm{NO}_{\mathrm{x}}$ emissions as a function of engine speed for a fixed brake torque of $40 \mathrm{Nm}$ (2.82 bar BMEP).

Figure 15: $\quad \mathrm{CO}$ emissions of GEM blends as a function of engine speed for a fixed brake torque of $40 \mathrm{Nm}$ (2.82 bar BMEP).

Figure 16: Knock limited spark advance of all GEM blends and components. 


\begin{tabular}{|c|c|c|c|c|}
\hline & $\begin{array}{l}\text { Blend A } \\
\text { (E85) }\end{array}$ & $\begin{array}{l}\text { Blend B } \\
\text { (G29,5E42,5M28) }\end{array}$ & $\begin{array}{l}\text { Blend C } \\
\text { (G37E21M42) }\end{array}$ & $\begin{array}{l}\text { Blend D } \\
\text { (M57) }\end{array}$ \\
\hline \multicolumn{5}{|l|}{ Property } \\
\hline Oxygen content [m\%] & 23,34 & 22,74 & 22,38 & 22,54 \\
\hline Gravimetric LHV [MJ/kg] & 29,22 & 29,48 & 29,66 & 29,53 \\
\hline Volumetric LHV [MJ/I] & 22,82 & 22,79 & 22,81 & 22,59 \\
\hline $\mathrm{AFR}_{\text {stoich }}[\mathrm{kg} / \mathrm{kg}]$ & 9,72 & 9,76 & 9,8 & 9,73 \\
\hline$\Delta \mathrm{h}_{\text {vap }}[\mathrm{kJ} / \mathrm{kg}]$ & 762,4 & 762,7 & 761,5 & 770,8 \\
\hline$\alpha(\# \mathrm{H} / \# \mathrm{C}$ in fuel) & 2,83 & 2,86 & 2,87 & 2,9 \\
\hline Specific $\mathrm{CO}_{2}$-emission $[\mathrm{g} / \mathrm{MJ}]$ & 71,69 & 71,56 & 71,49 & 71,41 \\
\hline
\end{tabular}

Table 1: Properties of the GEM blends 


\begin{tabular}{|l|l|l|l|}
\hline Property & Gasoline & Methanol & Ethanol \\
\hline Chemical formula & Various & $\mathrm{CH}_{3} \mathrm{OH}$ & $\mathrm{C}_{2} \mathrm{H}_{5} \mathrm{OH}$ \\
\hline Oxygen Content by mass (\%) & 0 & 49,93 & 34,73 \\
\hline Density at NTP (kg/l) & 0,74 & 0,79 & 0,79 \\
\hline Lower heating value (MJ/kg) & 42,90 & 20,09 & 26,95 \\
\hline Volumetric Energy Content $(\mathrm{MJ} / \mathrm{l})$ & 31,70 & 15,90 & 21,29 \\
\hline Stoichiometric AFR (kg/kg) & 14,4 & 6,5 & 9,0 \\
\hline Energy per unit mass of air $(\mathrm{MJ} / \mathrm{kg})$ & 2,98 & 3,09 & 2,99 \\
\hline Research Octane Number $(\mathrm{RON})$ & 95 & 109 & 109 \\
\hline Motor Octane Number (MON) & 85 & 88,6 & 98 \\
\hline Sensitivity (RON-MON) & 10 & 20,40 & 11 \\
\hline Boiling point at 1 bar $\left({ }^{\circ} \mathrm{C}\right)$ & $25-215$ & 65 & 79 \\
\hline Heat of vaporization (kJ/kg) & $\sim 305$ & 1100 & 838 \\
\hline Reid vapour pressure (psi) & 7,00 & 4,60 & 2,30 \\
\hline Mole ratio of products to reactants ${ }^{\mathrm{a}}$ & 0,937 & 1,061 & 1,065 \\
\hline Flammability limits in air $(\lambda)$ & $0,26-1,60$ & $0,23-1,81$ & $0,28-1,91$ \\
\hline Laminar burning velocity at NTP, & 33,0 & 40,0 & 38,5 \\
\hline Adiabatic flame temperature $\left({ }^{\circ} \mathrm{C}\right)$ & 2002 & 1870 & 1920 \\
\hline Specific CO ${ }_{2}$ emissions $(\mathrm{g} / \mathrm{MJ})$ & 73,95 & 68,44 & 70,99 \\
\hline Includes atmospheric nitrogen. NTP: normal temperature & \\
\hline
\end{tabular}

Table 2: Properties of typical gasoline, methanol and ethanol relevant to internal combustion engines. 


\begin{tabular}{|l|l|l|}
\hline Engine type & Volvo 1.8I & Audi/NSU \\
\hline Cylinders & 4 in-line & 1 \\
\hline Valves & 16 & 2 \\
\hline Valvetrain & DOHC & OHC \\
\hline Bore & $83 \mathrm{~mm}$ & $77.5 \mathrm{~mm}$ \\
\hline Stroke & $82.4 \mathrm{~mm}$ & $86.4 \mathrm{~mm}$ \\
\hline Displacement & $1783 \mathrm{cc}$ & $407.3 \mathrm{cc}$ \\
\hline CR & $10.3: 1$ & $13.13: 1$ \\
\hline Injection & PFI & PFI \\
\hline Induction & Atmospheric & Atmospheric \\
\hline ECU & MoTeC & MoTeC M4 \\
& M800 & \\
\hline
\end{tabular}

Table 3: Engine specifications. 


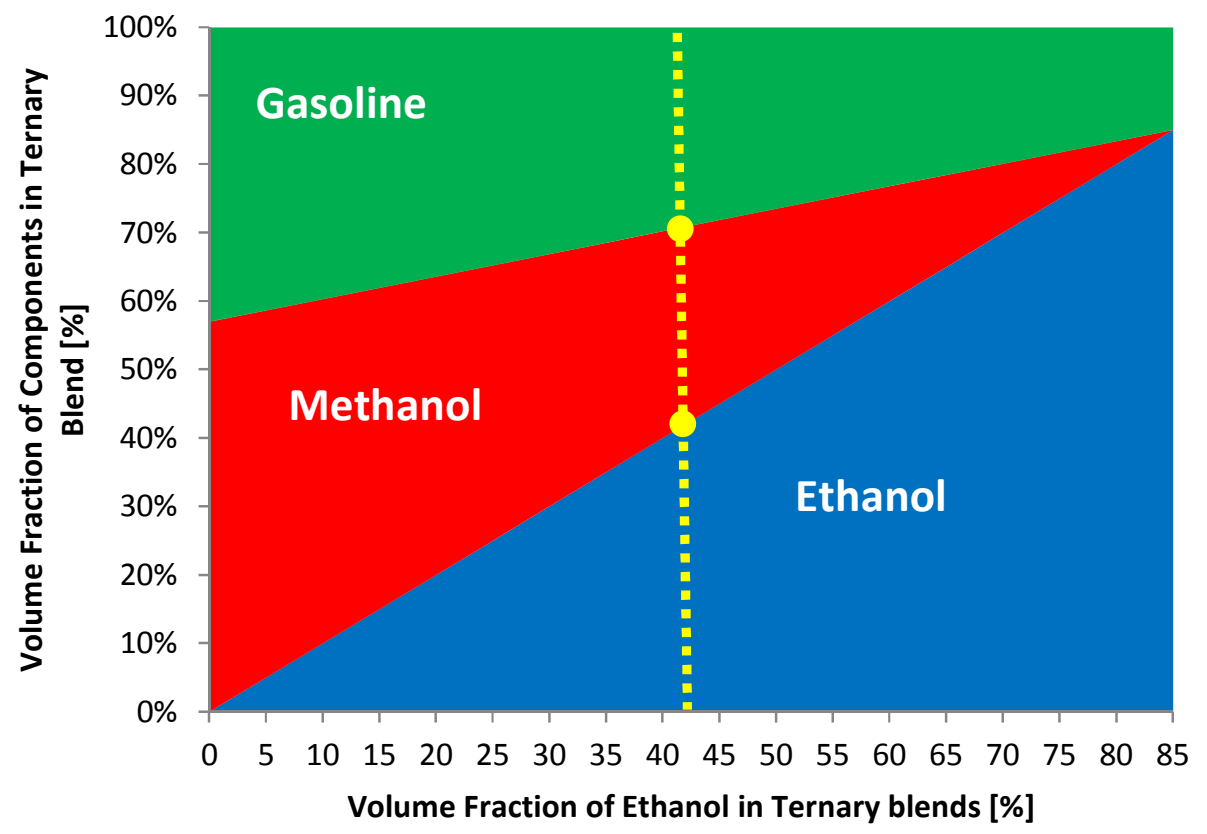

Figure 1: iso-stoichiometric GEM blends equivalent to conventional E85 [15]. 


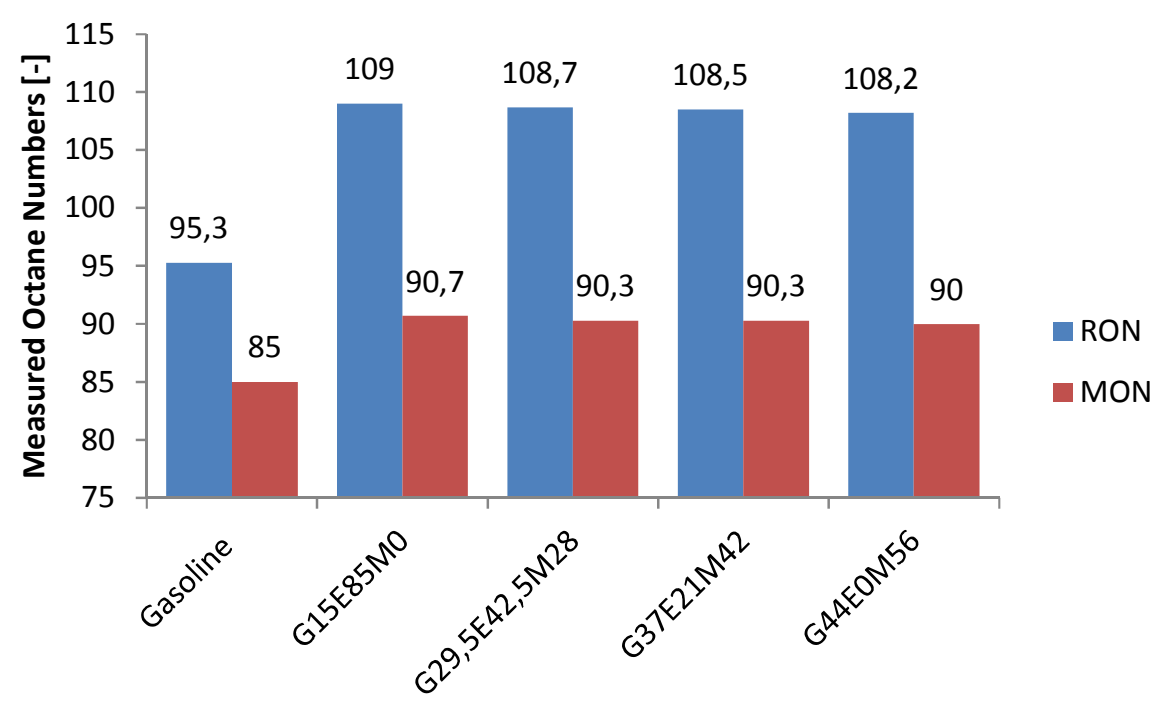

Figure 2: Measured Research (RON) and Motor (MON) octane numbers for each of the blends [7]. 


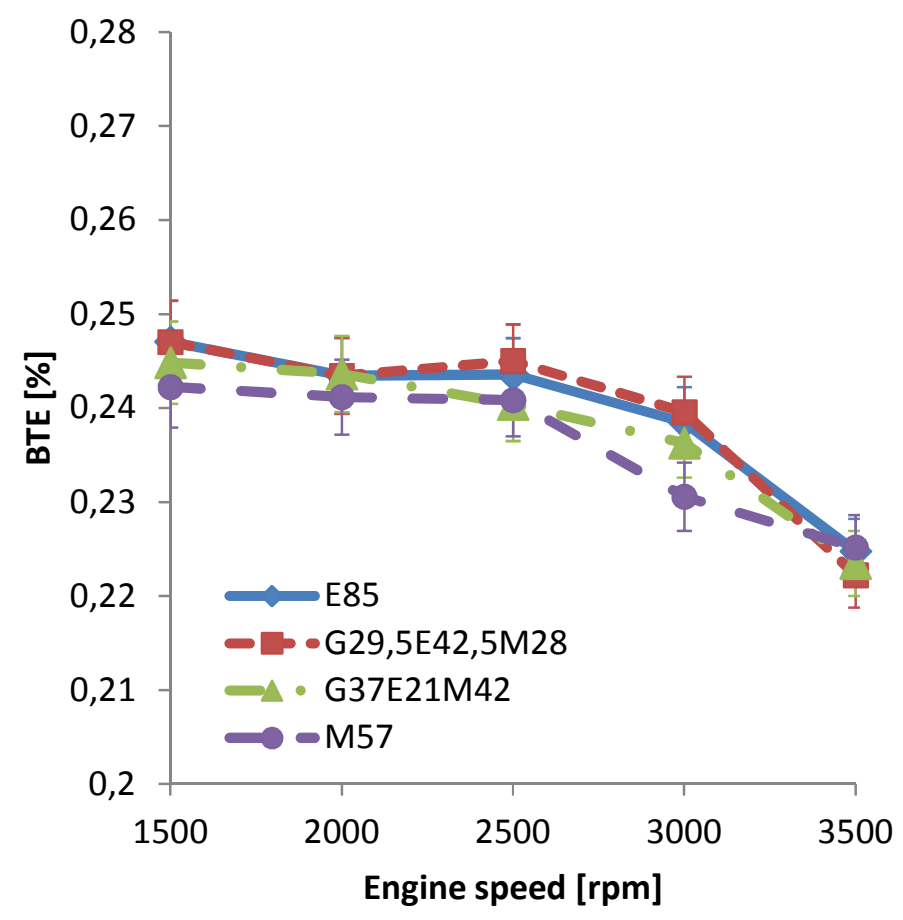

Figure 3: Brake thermal efficiency of GEM blends as a function of engine speed for a fixed brake torque of $40 \mathrm{Nm}$ (2.82 bar BMEP). 


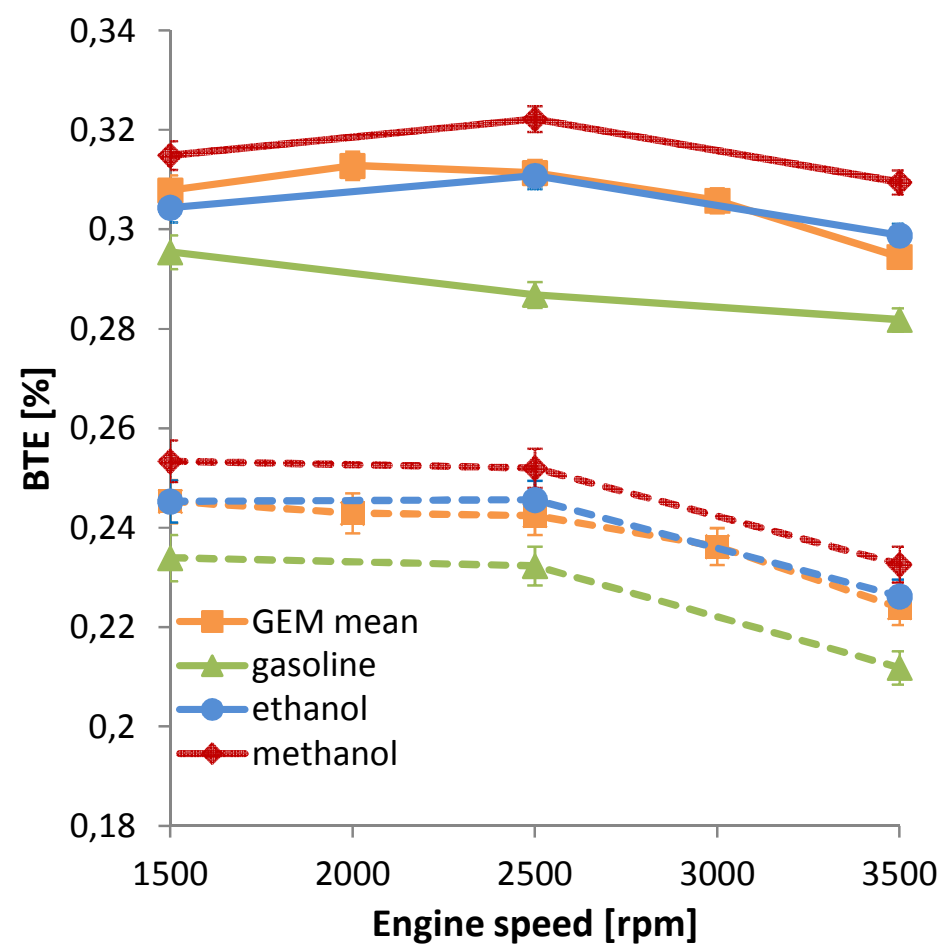

Figure 4: Brake thermal efficiency as a function of engine speed for different fixed brake torques of $40 \mathrm{Nm}(--)$ and $80 \mathrm{Nm}(-)$. 


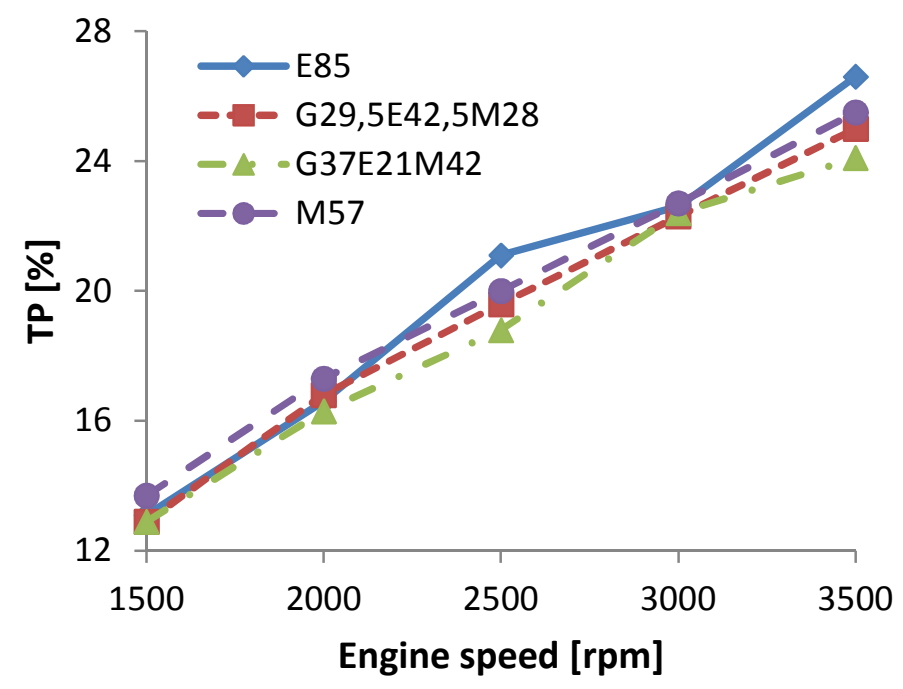

Figure 5: Throttle position of GEM blends as a function of engine speed for a fixed brake torque of $40 \mathrm{Nm}$ (2.82 bar BMEP). 


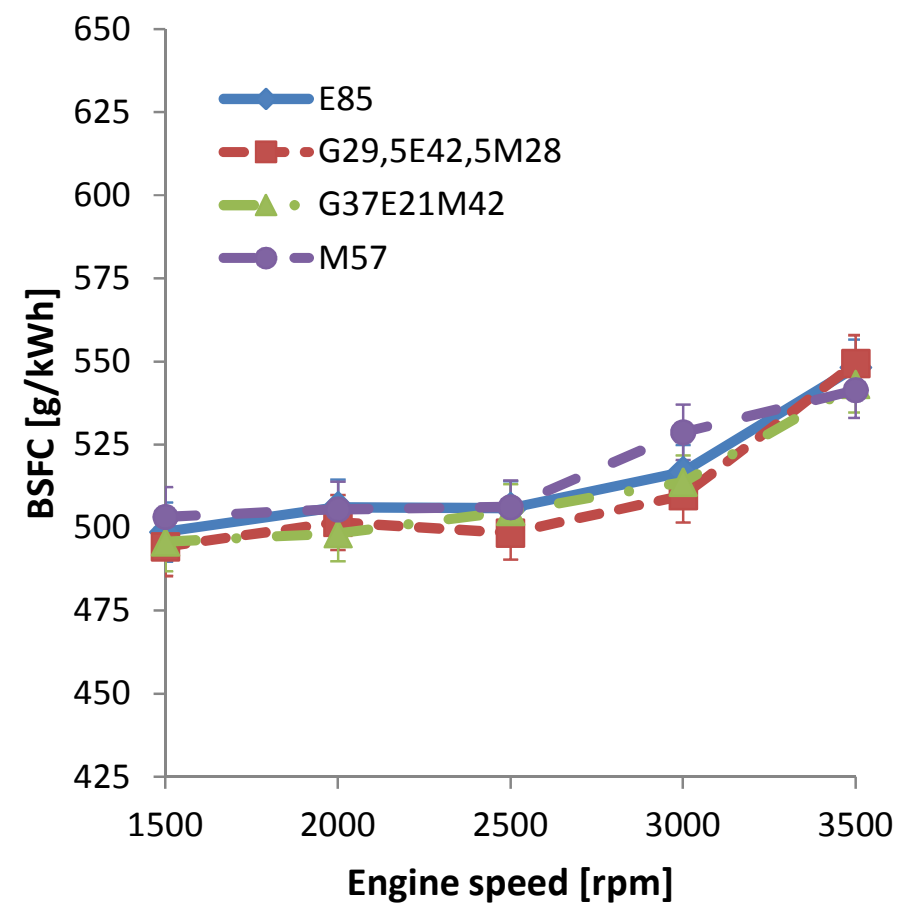

Figure 6: Brake specific fuel consumption of GEM blends as a function of engine speed for a fixed brake torque of $40 \mathrm{Nm}$ (2.82 bar BMEP). 


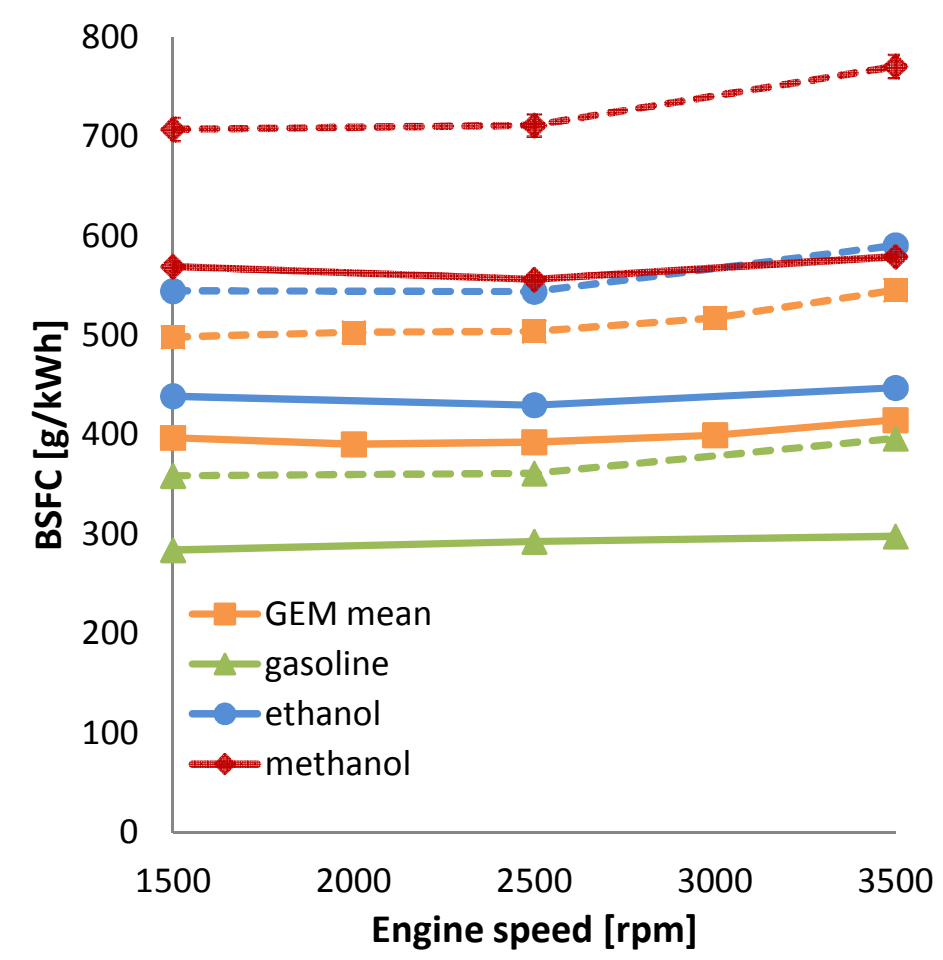

Figure 7: Brake specific fuel consumption as a function of engine speed for different fixed brake torques of $40 \mathrm{Nm}(--)$ and $80 \mathrm{Nm}(-)$. 


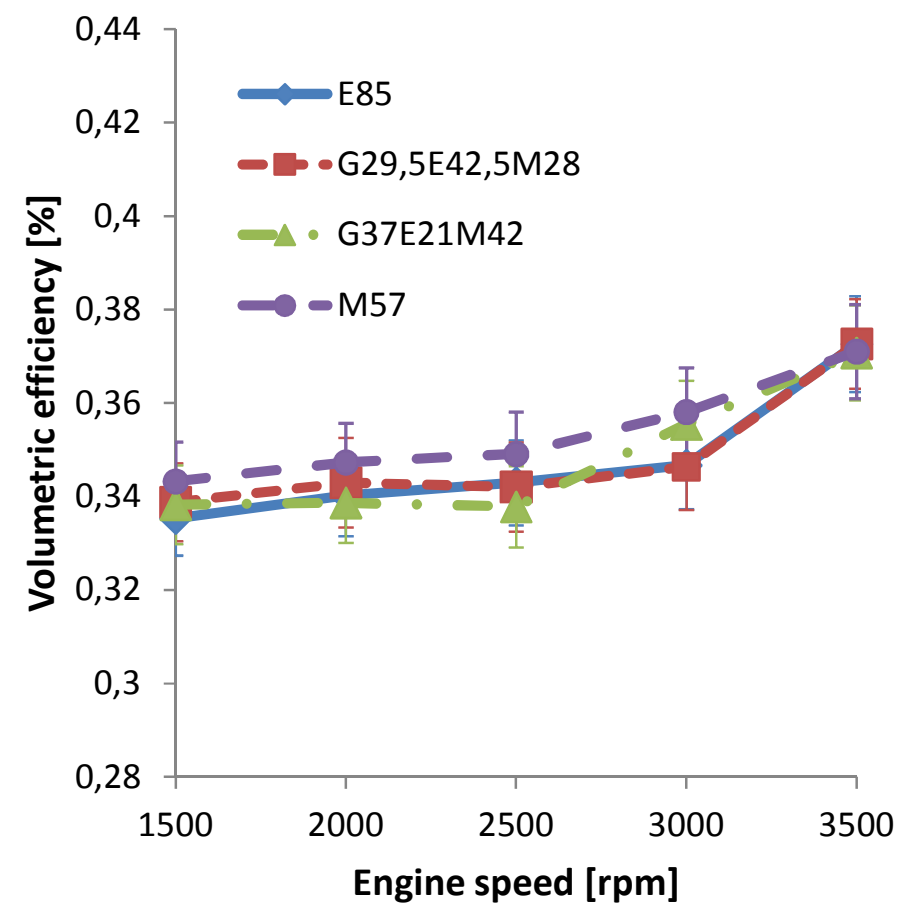

Figure 8: Volumetric efficiency of GEM blends as a function of engine speed for a fixed brake torque of $40 \mathrm{Nm}$ (2.82 bar BMEP). 


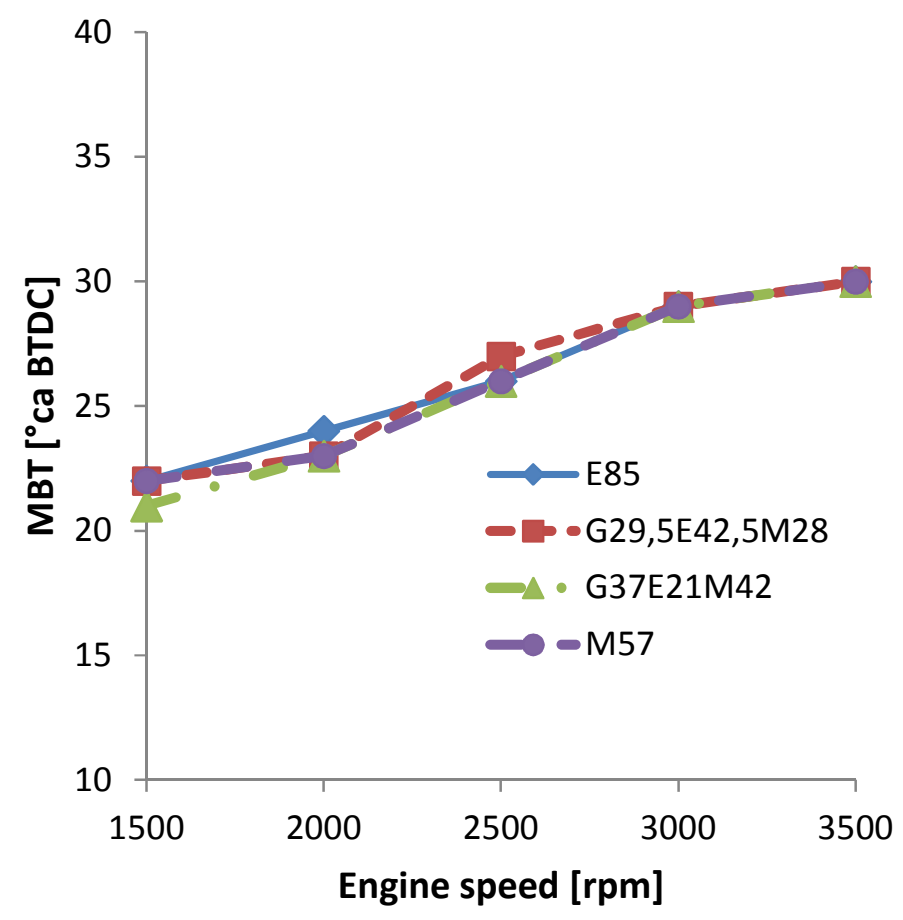

Figure 9: MBT of GEM blends as a function of engine speed for a fixed brake torque of $40 \mathrm{Nm}$ (2.82 bar BMEP). 


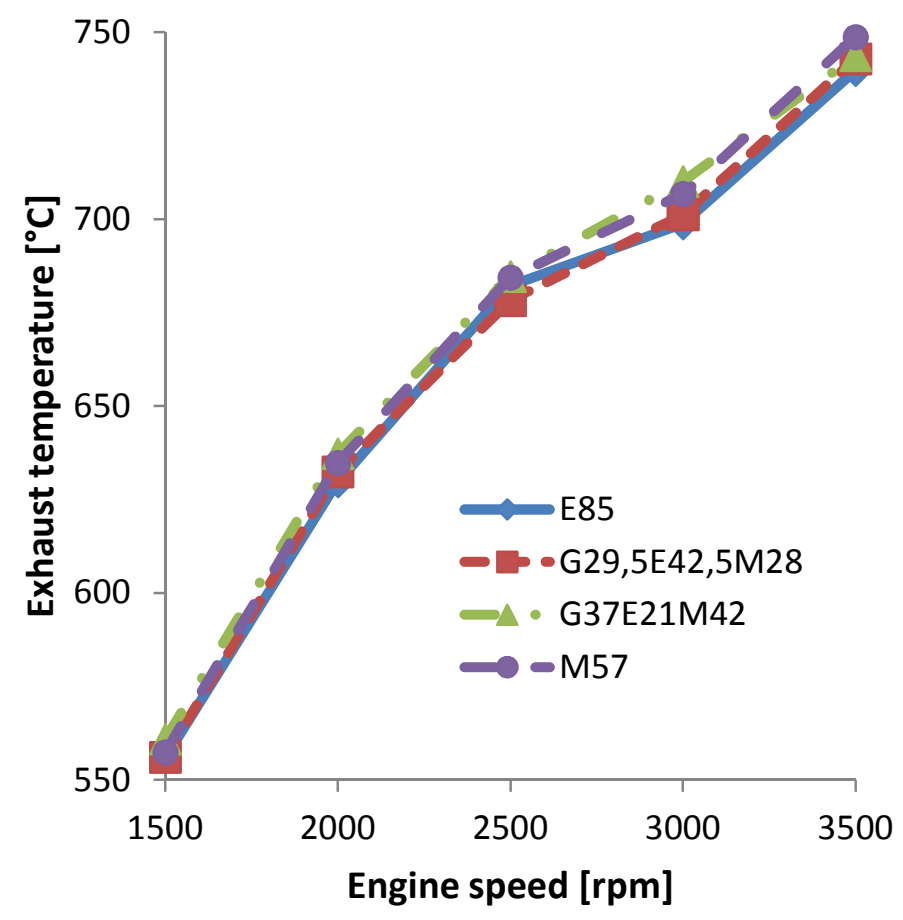

Figure 10: Exhaust temperatures of GEM blends as a function of engine speed for a fixed brake torque of $40 \mathrm{Nm}$ (2.82 bar BMEP). 


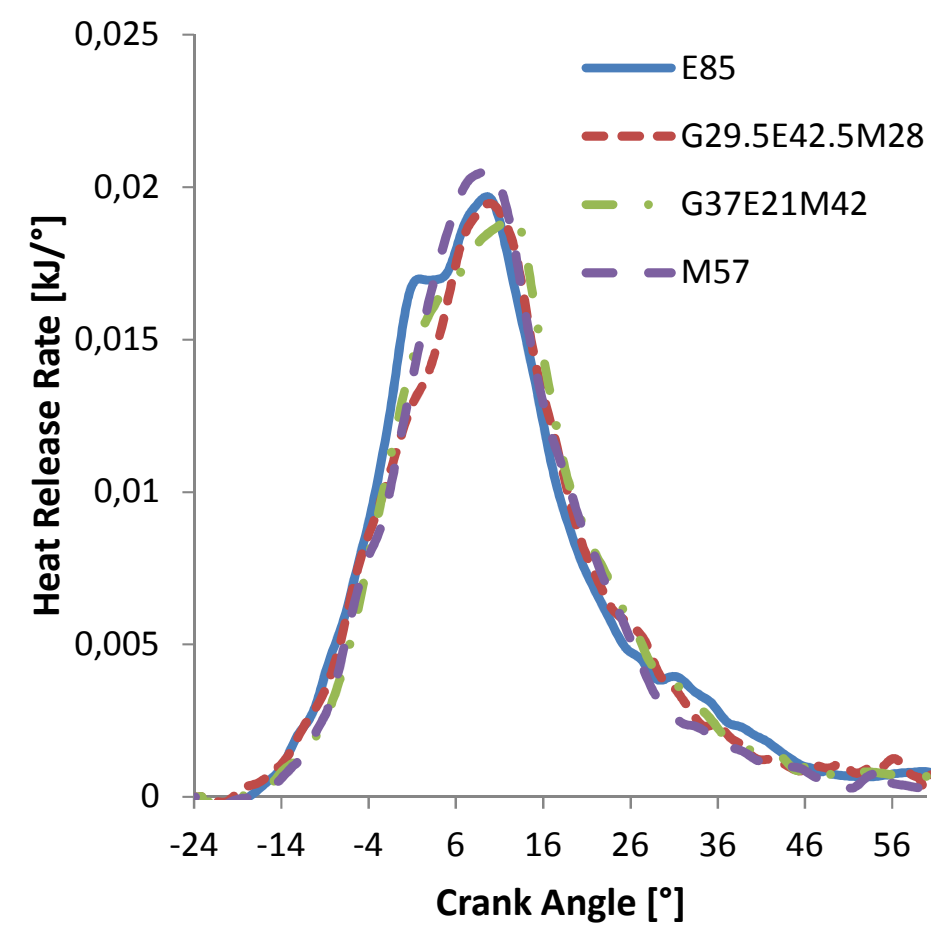

Figure 11: Heat release rates of GEM blends for an engine speed of $2000 \mathrm{rpm}$ and a fixed brake torque of $40 \mathrm{Nm}$ (2.82 bar BMEP). 


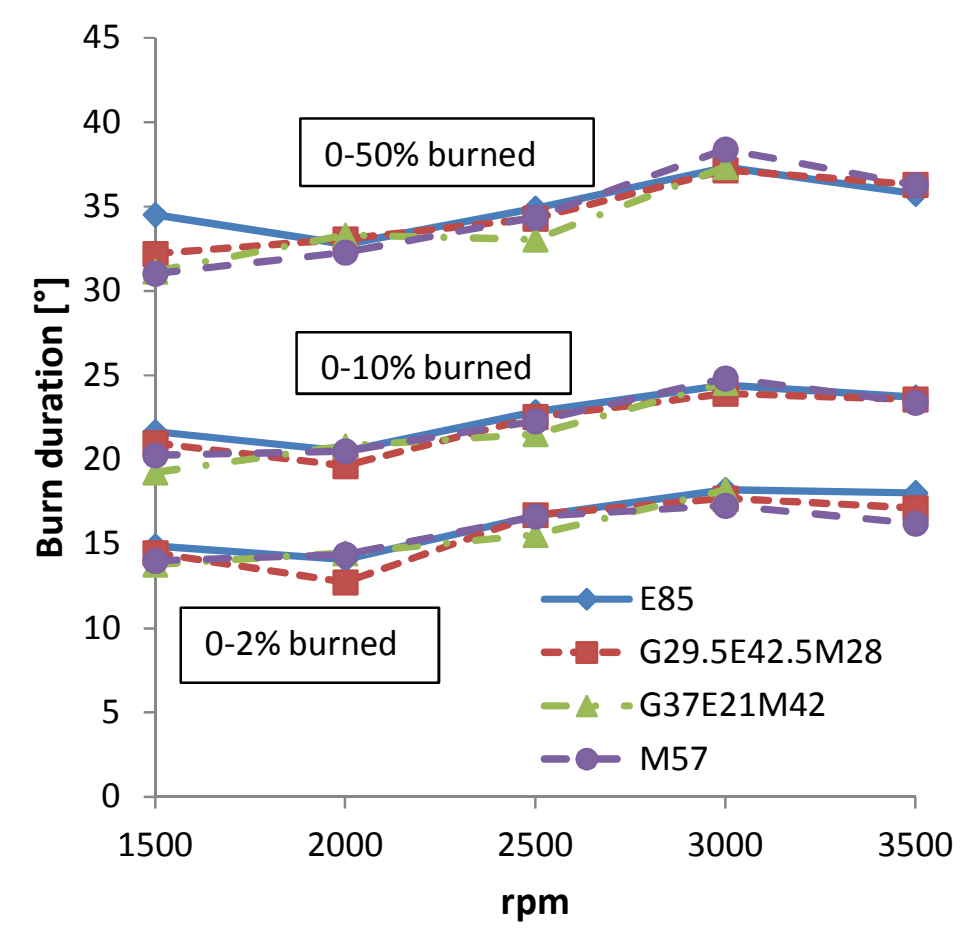

Figure 12: Ignition delay ( $0-2 \%$ burned), $0-10 \%$ and $0-50 \%$ burn duration of GEM blends as a function of engine speed for a fixed brake torque of $40 \mathrm{Nm}$ (2.82 bar BMEP). 


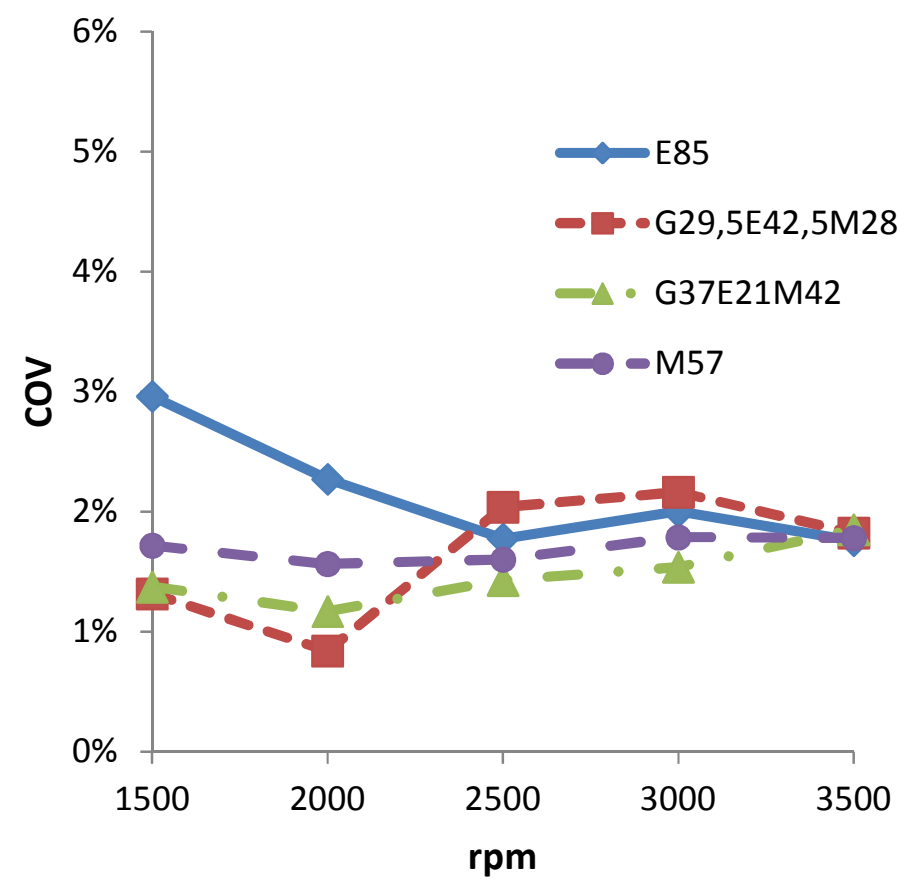

Figure 13: Coefficient of variation of the IMEP of GEM blends as a function of engine speed for a fixed brake torque of $40 \mathrm{Nm}$ (2.82 bar BMEP). 


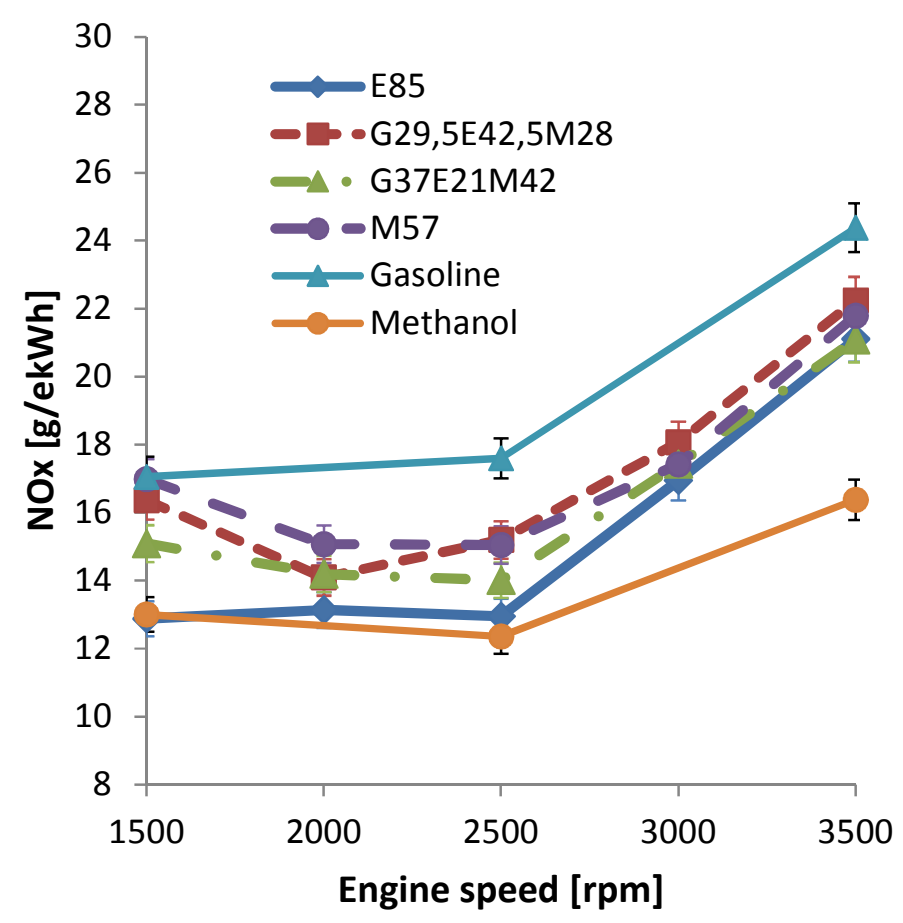

Figure 14: $\mathrm{NO}_{\mathrm{x}}$ emissions as a function of engine speed for a fixed brake torque of $40 \mathrm{Nm}(2.82$ bar BMEP). 


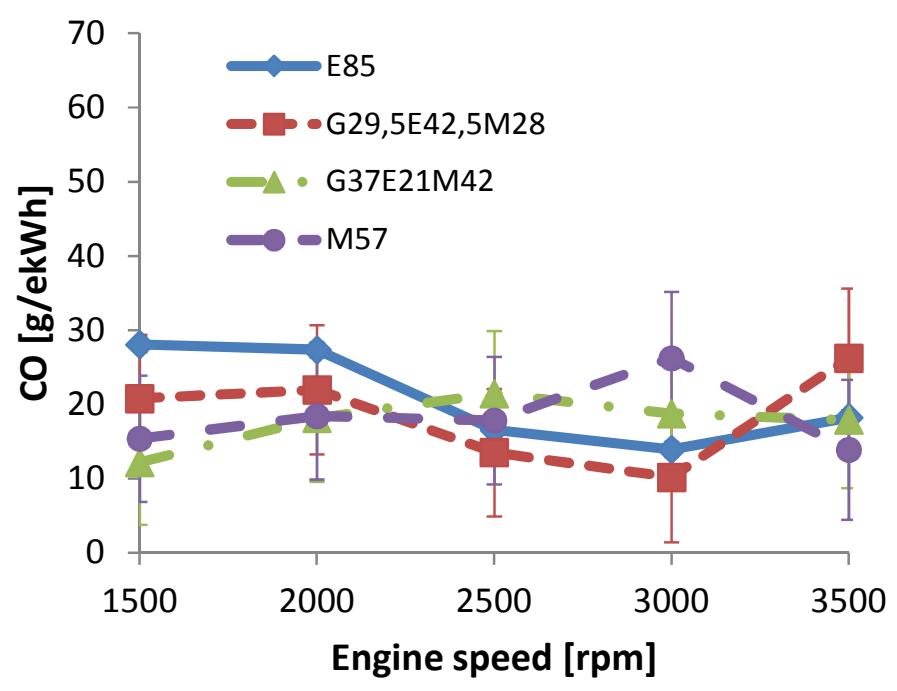

Figure 15: $\mathrm{CO}$ emissions of GEM blends as a function of engine speed for a fixed brake torque of $40 \mathrm{Nm}$ (2.82 bar BMEP). 


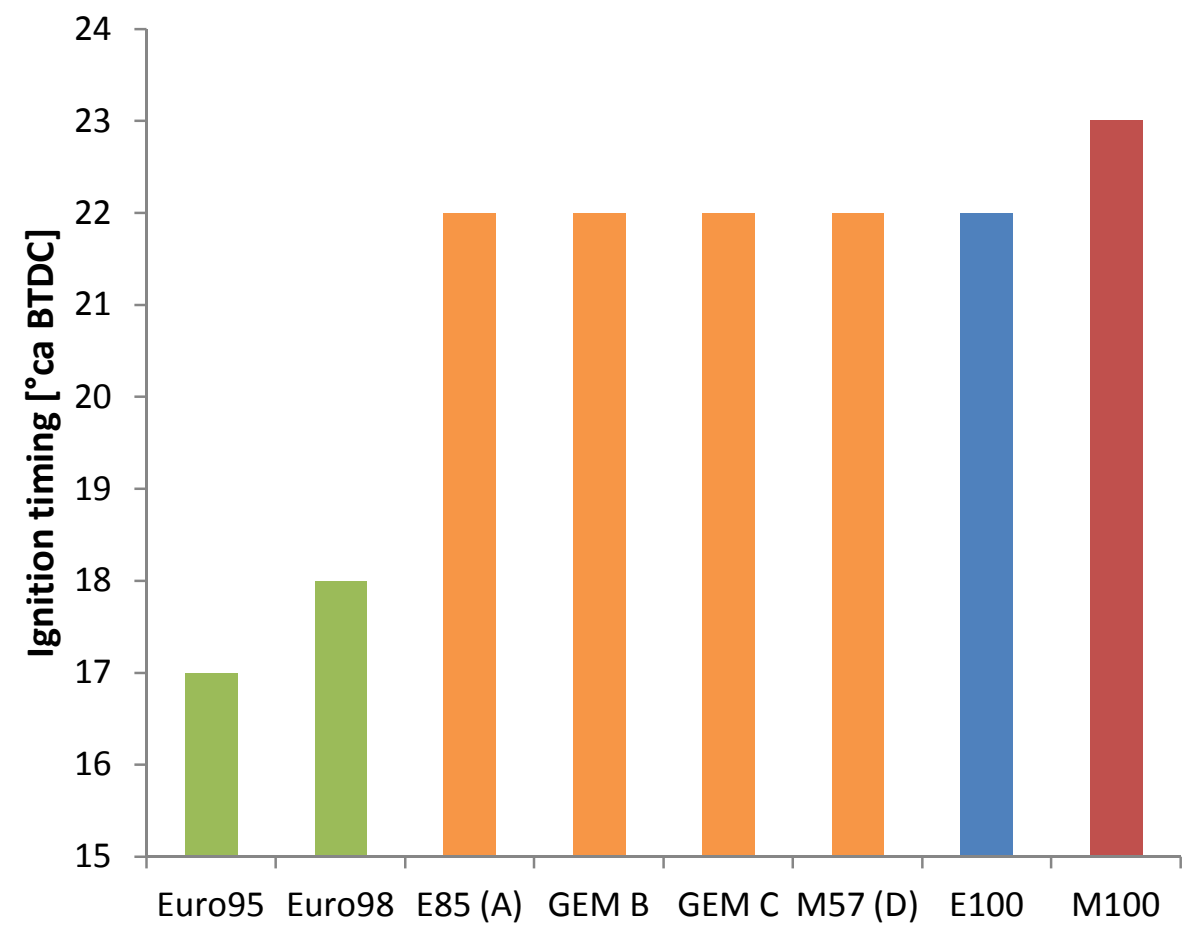

Figure 16: Knock limited spark advance of all GEM blends and components. 